\title{
Chronic inflammatory states: their relationship to cancer prognosis and symptoms
}

\author{
N MacDonald \\ Professor, Oncology, Gerald Bronfman Centre for Cinical Research in Oncology, McGill University, Montreal, Canada
}

This review is based on a presentation given by Professor MacDonald at the RCPE Palliative Care Symposium on 28 March 2011.

\begin{abstract}
A chronic inflammatory state (CIS) commonly accompanies advanced cancers. Elements of a CIS include aberrant immune system activity and changes in hypothalamic-neuroendocrine control mechanisms. The end result is stimulation of tumour growth and metastases. In addition to tumour stimulation, cancer symptoms may be enhanced. While for most symptoms correlation with a CIS remains tenuous, clearly a CIS is linked to the aetiology of the cancer anorexiacachexia syndrome. To date clinical studies aimed at a CIS are modest, but the increased understanding of the partnership of a CIS, cancer progression and anorexia-cachexia must lead to targeting a CIS in concert with conventional efforts to directly destroy tumour tissue.
\end{abstract}

KEYWORDS Cancer prognosis, chronic inflammation and cancer, autonomic nervous system changes in cancer

DECLARATION OF INTERESTS No conflict of interests declared.

\author{
Correspondence to $\mathbf{N}$ MacDonald, \\ Gerald Bronfman Centre for \\ Clinical Research in Oncology, \\ McGill University \\ 546 Pine Avenue West \\ Montreal, Quebec, \\ Canada
}

tel. +l 5143988988

e-mail neil.macdonald@mcgill.ca
This oncologist through most of his career held the view, perhaps shared by others, that evidence of an immune reaction around a tumour was a favourable finding. Even in those patients with far advanced cancers, this accumulation of myeloid cells, lymphocytes, macrophages and fibroblasts represented a valiant defense against the inevitable.

My views changed sharply after reading a 2001 paper by Balkwill and Mantovani' which mustered the evidence that rather than attacking an advanced cancer, immune cells were more often complicit in stimulating cancer growth and metastases. We were reminded that chronic inflammation commonly establishes the soil for malignant transformation. Examples include chronic bowel and respiratory conditions and a host of chronic viral illnesses.

Clearly an acute inflammatory response is key to our survival. There are two components to this response; mobilisation of the innate immune system, followed by activation of the adaptive component. Innate immunity is the body's first line of defence against injury or invasion of a pathogen. A range of leukocytes are attracted to the injury site; many produce cytokines, which stimulate angiogenesis and factors encouraging cell proliferation needed for repair. Innate system activity is followed by the adaptive response, characterised in part by the rallying of cytotoxic $T$ cells with the capacity to identify foreign antigens and to attack and kill cells or organisms demonstrating those antigens. Cells in each system may adopt a T-helper (Th) type I or 2 mode of action; for example ThI macrophages produce cytokines (e.g. interleukin [IL]-I2, IL-I5) which enhance cytotoxic T cell production, while Th2 oriented macrophages produce cytokines (e.g. IL-6, IL-4) which counter Th I actions and stimulate cell and blood vessel growth. ${ }^{2,3}$ The principal leukocyte populations in and around an advanced tumour are listed in Table I.

Normally, acute inflammation subsides with the repulse of an invading pathogen and repair of damaged tissue. However if the tap is left on and a systemic chronic inflammatory state (CIS) ensues, dire consequences follow. A CIS commonly accompanies many chronic illnesses including chronic heart failure, chronic obstructive pulmonary disease, chronic renal failure, Alzheimer's Disease and elderly fragility states. Markers of chronic inflammation are also found in the caretakers of the chronically ill.

\section{TUMOUR MICROENVIRONMENT}

Immune cells of the innate and adaptive systems are attracted to the tumour milieu. Components of the innate and adaptive system may marshal immune defences to attack cancer cells when tumours are localised and surgically resectable. In these circumstances the beneficial effects of lymphocyte infiltration into the 
TABLE I Innate and adaptive immune cells involved in regulating tumour growth (With permission. Disis $M$. Immune regulation of cancer. J Clin Oncol 2010;28:4532)

\begin{tabular}{|l|l|}
\hline Stimulate cancer growth & Inhibit cancer growth \\
\hline Innate immune cells & \\
\hline Neutrophils & Dendritic cells* \\
\hline Macrophage (M2) & Macrophage (MI) \\
\hline $\begin{array}{l}\text { Myeloid-derived } \\
\text { suppressor cells }\end{array}$ & \\
\hline Adaptive immune cells & \\
\hline Th2 CD4+ T cell & Cytotoxic CD8+ T cell \\
\hline CD4+ T regulatory cell & ThI CD4+ T cell \\
\hline B lymphocytes* & ThI7 CD4+ T cell \\
\hline $\begin{array}{l}\text { Abbreviation:Th=T-helper. } \\
\text { *Have been associated with both stimulation and inhibition. }\end{array}$ \\
\hline
\end{tabular}

tumour has been demonstrated. ${ }^{4}$ Studies to enhance tumour antigenicity and to stimulate immune cell response to tumours occupy the attention of many research laboratories today. ${ }^{5}$

The immune response to advanced cancer is usually not helpful. Many immune cells may produce cytokines that, as occurs with acute inflammation, enhance new vessel formation and local cellular growth. Now however, those characteristics are unwelcome, as they enhance tumour progression and neo-vascularisation furthers metastatic seeding. Moreover, cancer cells also acquire the ability to make pro-inflammatory cytokines. In light of current knowledge, most cytokines will stimulate cancer progress, some stimulate cells to mount a cytotoxic tumour response, and some have more nuanced dual actions, either favouring or limiting tumour activity depending on constantly changing local biologic circumstances. ${ }^{6}$

The primary cause of a CIS is not known. We do know that contributory chemokine and cytokine production does not resemble an orderly cascade where one begets another in linear fashion. Rather, a 'vicious circle' model exists whereby cytokines may induce selfpropagation through intermediaries which in themselves promote inflammation. The STAT3 intra-cellular transcription system provides an excellent example. interleukin-6 (IL-6) once induced, will in turn upregulate STAT3 which, in addition to other pro-inflammatory activity, will stimulate further production of II-6. A dynamic panorama, constantly in flux, is present. ${ }^{7}$

\section{IMMUNO-ENDOCRINE ABERRATIONS}

Reflecting the complexity of a CIS, a number of noncytokine partners are key participants. Aberrant activity of the hypothalamic-neuroendocrine system is a hallmark of a CIS. Typically, there is increased corticotrophin/ cortisol production, but the normal diurnal cortisol rhythms are often altered. ${ }^{8}$ Testosterone is commonly reduced, particularly in males on opioids. Both central and gonadal failure may be exhibited, differing from patient to patient. ${ }^{9}$ Both cortisol and testosterone have anti-inflammatory properties, although changes in diurnal production appear to blunt the cortisol effect.

Alterations in hypothalamic regulation of the autonomic nervous system have major effects. Catecholamine production is often increased in advanced cancer patients while vagal tone is reduced. Although norepinephrine and epinephrine are essential to the acute 'fight or flight' situation, their influence is malign in a CIS as they stimulate cancer cell growth and metastatic activity; ${ }^{10}$ dopamine has an opposite effect in keeping with the balanced physiologic systems observed in all aspects of human physiology."

Enhanced catecholamine activity is in the ascendancy as tumours progress. There are many animal studies which support this concept. Examples include:

I. Tumour growth: A seminal report by Riley on the protective effects of stress relief on the growth of the Bittner virus induced breast cancer in mice. ${ }^{12}$

Lee et al: Ovarian cancer cells in nude mice surgical stress promotes tumour size and volume which is attenuated by propanolol, a beta blocker. ${ }^{13}$

2. Metastases: Sloan et al. Breast cancer mouse model - a thirty-fold increase in metastases was induced by chronic stress (restraint). The process is mediated by a macrophage population which induced gene expressions giving tumour cells metastatic potential. Beta-adrenergic upregulation is key as a betaantagonist, propanolol, inhibits the process. ${ }^{14}$

3. Inflammatory cytokines: Yang et al. Human melanoma line - norepinephrine upregulated vascular endothelial growth factor (VEGF), IL-6 and IL-8 production together with upregulation of $\beta \mathrm{I}$ and $\beta 2$ adrenergic receptors. ${ }^{15}$

4. Tumour immunity: Norepinephrine and cortisol promote a switch from the Thl immune pattern to Th2 pattern with consequent decrease in immune defences against tumours. ${ }^{16}$

\section{Human evidence}

Here studies are less consistent and open to conflicting interpretations. Some evidence of note:

I. Effects of childhood stress: Long-term adverse childhood experiences (examples include family strife, parental drug/alcohol addiction, physical abuse) can leave a lasting effect upon victimised children. In adult life these children may be subject 
to illnesses commonly associated with chronic inflammatory states. ${ }^{17,18}$

2. Psycho-social therapies: In 1989 Spiegel et al reported in a randomised trial of metastatic breast cancer patients that group counselling improved both quality and length of life in the treatment group. ${ }^{19}$ Subsequently, efforts to repeat this finding using his exact method or other counselling initiatives have yielded negative uncertain results. ${ }^{20,21}$ Almost all studies involve breast cancer patients who may have lower inflammatory profiles. Fawzy published a positive clinical trial which enlisted advanced melanoma patients. ${ }^{22}$

3. Social isolation and support: The weight of evidence suggests that social isolation and lack of social support increases the incidence of adult chronic inflammatory states. ${ }^{23,24}$

4. Beta blocker studies in breast cancer: A recent retrospective study reports that newly diagnosed breast cancer patients who happen to be on a beta blocker have a prolonged disease-free interval and possibly increased overall survival. The effect is most marked in the worst prognostic group: those with 'triple-negative' markers. ${ }^{25}$ The type of beta blocker may be important, as propanolol, not atenolol, was associated with survival in one study. ${ }^{26}$ Beta blockers do not appear to influence tumour initiation, but seem to cut down primarily on the rate of tumour growth and metastases formation. ${ }^{27}$

\section{CHRONIC INFLAMMATORY STATE MARKERS}

We are in an era of personalised medicine, a time when we search for biologic markers which help us tailor therapies for patients after analysing the biologic characteristics of their tumours.

The presence of a CIS is readily detected by simple, inexpensive tests. C-reactive protein (CRP), a circulating acute phase liver protein, is the most studied inflammatory marker, linked as it is to inflammatory cytokine activity, notably IL-6. C-reactive protein is one of a family of acute phase proteins (APP). Fibrinogen, an APP, when increased, also connotes a poor prognosis. Other footprints include high neutrophil-lymphocyte ratios, high platelet-lymphocyte ratios and low albumin; the latter is usually a late finding in advanced cancer patients. Research is underway to link these test results into clinically useful prognostic systems. Combinations linking CRP-albumin or CRP-neutrophil counts appear to be the best prognostic scales. ${ }^{28}$ The modified Glasgow Prognostic Score (mGPS) is finding its way into practice and has been validated by several groups. Scottish teams (led by DC McMillan and K Fearon) are the leaders in this field. McMillan and colleagues have convincingly demonstrated that when a baseline CIS is present, regardless of stage, the patient's future is likely to be grim. ${ }^{29}$ Is this outcome solely because of the tumour stimulating effects of a CIS? Perhaps not; a modest body of work suggests that a CIS can interfere with the pharmacokinetics and pharmacodynamics of certain chemotherapy drugs. ${ }^{30,31}$ The impact on trial participation and drug response is not known, although a few small trials suggest that both the likelihood of a patient completing a course of therapy and benefitting from it may be compromised. ${ }^{32-35}$

\section{INFLAMMATION: INFLUENCE ON CANCER SYMPTOMS}

A CIS is associated with many cancer symptoms; three are selected for further discussion.

\section{Sleep}

Insomnia is a common complaint of cancer patients. Its consequences of increased time for worrisome ruminations and daytime fatigue are clearly evident. Insomnia has more ominous connotations as it is sometimes a manifestation of an underlying CIS. Poor sleep is associated with a raised CRP, while inflammation is known to further disturb sleep patterns. ${ }^{36}$

Sleep disturbance also interferes with circadian rhythms; sympathetic activity is increased and normal cortisol fluctuations are flattened. ${ }^{37} \mathrm{~A}$ single root cause is not clear, but it is certain that sleep interference links both patient distress and harmful underlying inflammatory activity.

Can controlling inflammation with better sleep hygiene and/or hypnotics break the vicious circle? The answer is unknown today; it is nevertheless sensible to employ our imperfect therapies to establish restful sleep as best we can while encouraging research on anti-inflammatory approaches to insomnia relief.

\section{Fatigue}

Chronic fatigue, unrelieved by rest, is among the most common causes of suffering, both in those with advanced cancer and in those with cancer amenable to treatment with chemoradiotherapy. ${ }^{38}$

A CIS, determined by inflammatory cytokine levels and neuroendocrine abnormalities may be a hallmark of some fatigue states. In healthy people (adolescents and short-term shift workers), increased norepinephrine correlates with a sense of fatigue..$^{39,40}$

Recently, Fagundes et $\mathrm{al}^{41}$ reported in a study of women receiving adjunct chemotherapy that $53 \%$ stated they were chronically fatigued some months after chemotherapy. These patients had significantly higher norepinephrine plasma levels and reduced heart rate variability (HRV) reflecting lowered vagal-parasympathetic 
activity at baseline and after a standard psychological stress test (giving a speech). Norepinephrine and HRV changes were not correlated, suggesting that sympathetic and parasympathetic tone may act independently to mediate fatigue.

Arguably, exercise is the only established therapy for cancer fatigue. Cardiovascular fitness is associated with increased vagal tone, as demonstrated by increased $\mathrm{HRV}^{42}$ This may be a mechanism whereby exercise improves chronic fatigue.

\section{The anorexia-cachexia syndrome}

The symptom complex most commonly linked with a $\mathrm{CIS}$ is the anorexia-cachexia syndrome (ACS). It is also one of the most devastating problems affecting the lives of advanced cancer patients and their families. The impact of the ACS is profound; it is commonly encountered across the spectrum of cancer, occurring in approximately $50 \%$ of advanced pancreas and lung cancer patients at the time of diagnosis. The ACS is less commonly encountered in breast cancer and lymphoma patients at presentation, with other cancer types ranging between these extremes. As death approaches, however, its incidence steadily increases across the board.

The ACS contributes directly to impaired quality of life, morbidity and mortality. A litany of adverse outcomes associated with ACS includes:

- $\quad$ Reduced functional capacity

- Increased adverse effects of therapy

- Decreased treatment options

- Dependency on family members and healthcare institutions

- Increased healthcare costs

A similar syndrome of decreased appetite, weight loss, fatigue and functional impairment is encountered in virtually all of the ultimately fatal non-malignant disorders, notably heart failure, chronic obstructive pulmonary disease, chronic renal failure and the frail elderly. In these disorders a CIS is also commonly present. This is an observation of practical import as studies on one disorder will translate into better understanding and therapies in the other disorders.

Wasting cancer patients have a plethora of reasons for reduced intake:

- Cognitive impairment, delirium

- Depression, fatigue

- Pain, dyspnoea

- Stomatitis, taste alteration

- Dry mouth

- Dysphagia, odynophagia

- Gastric stasis

- Bowel obstruction
- Nausea and vomiting

- Severe constipation

These contributory factors are packaged under the rubric of 'secondary cachexia' in distinction from the metabolic dysfunctions, often CIS-induced, grouped as 'primary cachexia'. While useful in the clinic (each secondary cause must be specifically identified, as distinct therapies apply) many of the secondary problems are probably closely linked to primary cachexia. For example, depression is linked to a CIS. ${ }^{43,44} \mathrm{~A}$ full range of bowel problems may relate to an altered sympathetic/ parasympathetic activity ratio.

\section{Anorexia}

Cancer patients suffer a host of symptoms that lower appetite. One eats poorly if in pain, struggling for breath, or with a bowel distended with stool. At the heart of cancer anorexia, however, is a centrally mediated process which contributes to the so-called secondary mechanisms outlined above but which, even in their absence, leave the patient with no interest in or indeed revulsion for food.

There are two main central nervous system (CNS) centres which control appetite:

The hypothalamus: There are neuronal pathways in and around the paraventricular and arcuate nuclei which control energy intake. Neurotransmitters in this region induce appetite, while an alternate set of neurotransmitters cause a sense of satiety when we have restored energy intake.This equilibrium is commonly disturbed in advanced cancer patients. ${ }^{45}$

The appetite-stimulating pathway is activated by peripheral messages relayed through the vagus nerve and by the circulating hormone, ghrelin, produced in the stomach. Hypothalamus cells are induced to produce neurotransmitters which produce a sense of hunger. When satisfied, an opposing system is turned on which negates interest in food ingestion. Prominent on this side of the equation is alpha melanocyte stimulating hormone $(\alpha M S H)$, which is a cleavage product of the proopiomelanocortin family and whose melanocyte activity is upregulated in cancer anorexia by cytokines, both circulating and produced locally by microglia. The most prominent cytokines in this process appear to be interleukin I- $\beta$ and Leukemia Inhibitory Factor (LIF). ${ }^{46}$ Following activation of the type 4 melanocortin receptor (MC4) by $\alpha \mathrm{MSH}$, a linkage between appetite suppression and increased energy expenditure is noted, ${ }^{47}$ a seeming paradox wherein appetite is poor, yet energy demand is elevated. Increased sympathetic activity may be important to this process.

The solitary tract nucleus (STN): This brainstem nucleus is involved in appetite regulation and bowel motility. Here, again, appetite stimulating and suppressing systems 
which mirror those in the hypothalamus are balanced in health. Vagal afferent information and circulating gut hormones such as cholecystokinin (an appetite suppressant) probably play a prominent role in STN regulation. The appetite suppression arm is, as in the hypothalamus, upregulated by cytokines; again IL- $\beta$ is key to this process. ${ }^{48}$

Cerebrum: Little is known about cerebral effects on appetite. Messages from the cerebrum are probably key in modulating our sense of food enjoyment. A virtual 'hedonistic centre' has been postulated in which endocannabinoids may be important. Marijuana induces 'the munchies' and may be operant here. Clinically, while marijuana research on energy intake is equivocal, a recent study reports that a cannabinoid may particularly enhance the taste of food. ${ }^{49}$

\section{Cachexia}

'Cachexia' is an oft misunderstood word interpreted variously by those who use it. Lack of clarity has held back research and clinical care. Recently an international expert group published a consensus statement on cachexia:

Cancer cachexia is a multi-factorial syndrome defined by an ongoing loss of skeletal muscle mass (with or without loss of fat mass) that cannot be fully reversed by conventional nutritional support and leads to progressive functional impairment. The pathophysiology is characterised by a negative protein and energy balance driven by a variable combination of reduced food intake and abnormal metabolism. ${ }^{50}$

One notes their emphasis on muscle loss, an emphasis I will follow.

The image of the severely wasted patient is familiar to both physicians and lay people. Not so apparent is the seemingly well-nourished obese patient whose fat mantle masks major muscle loss. Baracos' group, reviewing muscle mass quantified by routine computerised tomgraphy (CT) scans, have established that an obese cancer patient may have lost substantial muscle. As with the obviously wasted patient, the obese sarcopenic patient (using the simplified definition of sarcopenia as 'loss of muscle mass') is subject to diminished survival and treatment toxicity. ${ }^{51-53}$ Thus, regardless of the patient's general appearance, if muscle wastes, negative consequences in prognosis, therapeutic opportunities and function follow.

In the patient with the anorexia-cachexia syndrome, muscle tissue is subject to many insults. These include:

- Diminished nourishment and synthesis second to anorexia

- Increased loss of muscle protein

- A mismatch between muscle factors stimulating synthesis $(\downarrow)$ and breakdown $(\uparrow)$

- A downward spiral as patients progressively lose function as their capacity to exercise is reduced

A CIS is commonly a root cause of the above panorama. Prominent features of its multi-pronged assault include:

I. Gene activations culminating in upregulation of the ubiquitin proteasome complex. ${ }^{54}$ This is one of the principal systems involved in balancing muscle synthesis and proteolysis; as its activity increases, so does enzymatic breakdown of muscle. ${ }^{55}$ The resultant amino acids are exported to fuel glucose production in the liver (gluconeogenesis.) The increased availability of glucose is welcomed by tumour cells which have often changed their mode of metabolism from oxidative phosphorylation to aerobic/anaerobic glycolysis, processes which require large quantities of glucose. A variety of cytokines are implicated as gene modifiers. ${ }^{56}$

2. Inflammatory factors may also decrease the actions of anabolic stimuli (testosterone, growth hormone, insulin). ${ }^{56}$

3. Major contributors to the normal 'yin-yang' build-up and breakdown pattern in normal muscle are myostatin-activin (reduces synthesis and increases proteolysis) and MyoD (sustaining synthesis). ${ }^{57}$ Activin and myostatin are members of the TGF $\beta$ family which are upregulated, seemingly independent of other inflammatory cytokine action.

\section{Proteolysis inducing factor (PIF)}

This glycoprotein inhibits muscle synthesis and increases degradation, the latter effect by activating the ubiquitinproteasome system. It appears to be a tumour produced factor, apparently independent of host inflammation but it may induce liver cytokines. ${ }^{55}$ While established as a mouse factor and isolated from the urine of cachectic patients with cancer, its acceptance into the pantheon of factors causing cachexia has been controversial. Arguments have hinged on the lack of human capacity to glycosylate the core peptide normally present in humans. At present it appears that PIF is probably also a human cachectic agent, and it may be that glycosylation is limited to tumour cells.

\section{EMERGING THERAPIES}

While therapy will not be discussed in detail, new understanding of the anorexia-cachexia process will lead to more logical treatments. We have long had excellent appetite stimulants in corticosteroids and progestational agents; sadly they also induce muscle loss. To date there is no established therapy for the cachexia component. This scenario may change. 
The importance of regular exercise in preventing muscle loss and maintaining function is now realised. ${ }^{58}$ We no longer advocate that patients 'rest and preserve your strength'; rather increased activity within safe limits is stressed, together with increased intake of protein.

Drugs under study include:

I. Omega 3 fatty acids have a powerful inhibitory effect on many animal tumour models, presumably through their actions as inflammatory inhibitors. ${ }^{59}$ Human trials are not conclusive. ${ }^{60,61}$ Non-steroidal antiinflammatory drug (NSAID) studies are compelling. lbuprofen can reduce muscle loss in an elderly rat model. Lundholm's group reported in a series of studies the beneficial effects of indomethacin on cancer patient symptoms, weight loss and survival. 62,63 This important body of work has not been sufficiently followed up by others. Future trials combining NSAIDs with other anti-inflammatory approaches are warranted.

2. Selective androgen receptor modifiers (SARMs). ${ }^{64}$

3. Vitamin D. ${ }^{65}$

4. Drugs that may enhance the muscle synthetic action of epinephrine-like drugs ( $\beta$-agonists, formoteral is an example). ${ }^{66}$

5. Drugs that block the adverse effects of undue sympathetic activation. Beta blockers increase adipose tissue in heart failure ${ }^{67}$ patients and inhibit muscle breakdown in burn patients. ${ }^{68}$ Herein lies another poorly understood paradox: which patients may benefit from seemingly opposing approaches? ${ }^{69}$

6. Inhibitors of specific cytokines, TNF antibodies are unsuccessful, IL-6 inhibition studies show potential. ${ }^{70}$

7. The most promising theme at present may be the reversal of activin-myostatin activity. At least four drugs have successfully reversed cachexia in rodent models with early promising phase I and II human trials. A recent article in Cancer Cell by Zhou et al excited great interest. ${ }^{71}$ Activin IL $\beta$ antagonist (a decoy receptor) not only reversed cachexia, but also resulted in longer survival of tumour-bearing mice, notwithstanding that their tumours continued to grow. This is the first clear evidence that specific reversal of muscle loss can prolong life.

\section{CONCLUSION}

In 2011 we can reach several conclusions on chronic inflammatory states:

- Immune response often facilitates tumour progression.

- Tumour cells produce inflammatory chemical mediators assisting growth.

- Inflammatory mediators enhance some cancer symptoms.

- There is evidence that anti-inflammatory agents may modify the course of cancer. ${ }^{72}$

- Will anti-inflammatory therapies improve life quality and quantity?

- Will relief of cachexia prolong survival?

Arising from these conclusions we can arrive at a logical set of approaches to the management of illness associated with a CIS.

- Impeccable symptom assessment and management from the point of diagnosis.

- Symptom care linked with other anti-chronic illness approaches from the time of diagnosis.

- Access to nutrition-rehabilitation programmes geared to strengthen and maintain function and control fatigue from the point of diagnosis.

- A change in research and educational priorities to reflect the importance of a CIS and commitment to interdisciplinary collaboration to optimise patient outcomes.

Our research priorities, certainly those controlled by the public purse, should be set to reflect the primacy of chronic inflammation and the need for programme research marrying specific efforts to kill cancer cells with optimal symptom control. 


\section{REFERENCES}

Balkwill F Mantovani A. Inflammation and cancer:back toVirchow? Lancet 200I; 357:539-45. doi: I0.1016/S0I40-6736(00)04046-0

2 De Visser KE, Eichten A, Coussens LM. Paradoxical roles of the immune system during cancer development. Nat Rev Cancer 2006; 6:24-37. doi:10.1038/nrcl 782

3 Disis ML. Immune regulation of cancer. I Clin Oncol 2010; 28(29):453I-38. doi:I0.I200/JCO.2009.27.2I46

4 Roxburgh CS, Salmond JM Horgan PG et al. The relationship between the local and systemic inflammatory responses and survival in patients undergoing curative surgery for colon and rectal cancers. J Gastrointest Surg 2009; 13:201 I-18; discussion 2018-19.

5 Cavallo F, De Giovanni C, Nanni P et al. 20I I: the immune hallmarks of cancer. Cancer Immunol Immunother 20I I; 60:3 I9-26. doi:|0.1007/ s00262-010-0968-0

6 Grivennikov SI, Greten FR, Karin M. Immunity, inflammation and cancer Cell 2010; 140:883-99. doi:10.1016/i.cell.2010.01.025

7 Grivennikov SI, Karin M. Dangerous liaisons:STAT3 and NF-kappaB collaboration and crosstalk in cancer. Cytokine Growth Factor Rev 2010; 21 : II-19 doi:10.1016/j.cytogfr.2009.11.005

8 Eismann EA, Lush E, Sephton SE. Circadian effects in cancerrelevant psychoneuroendocrine and immune pathways. Psychoneuroendocrinology 2010: 35:963-76. doi:10.1016/j. psyneuen.2009.12.01I

9 Skipworth RJ, Moses AG, Sangster K et al. Interaction of gonadal status with systemic inflammation and opioid use in determining nutritional status and prognosis in advanced pancreatic cancer. Support Care Cancer 201 I; 19:391-40I. doi:10.1007/s00520-010-0832-y

10 Armaiz-Pena GN, Lutgendorf SK, Cole SW et al. Neuroendocrine modulation of cancer progression. Brain Behav Immun 2009, 23:10-15. doi:10.1016/j.bbi.2008.06.007

I I Moreno-Smith M, Lu C, Shahzad MM et al. Dopamine blocks stressmediated ovarian carcinoma growth. Clin Cancer Res 20II; 17:364959. doi:I0.1 I58/I078-0432.CCR-I0-244I

12 Riley V. Mouse mammary tumors: alteration of incidence as apparent function of stress. Science 1975; |89:465-67. doi:|0.I I26| science. 168638

13 Lee JW, Shazad MM, Lin YG et al. Surgical stress promotes tumor growth in ovarian carcinoma. Clin Cancer Res 2009; 15:2695-702.

14 Sloan EK, Priceman SJ, Cox BF et al.The sympathetic nervous system induces a metastatic switch in primary breast cancer. Cancer Res 2010 70:7042-7052. doi:I0.1 I58/0008-5472.CAN-10-0522

15 Yang EV, Kim SJ, Donovan EL et al. Norepinephrine upregulates VEGF, IL-8, and IL-6 expression in human melanoma tumor cell lines: implications for stress related enhancement of tumor progression. Brain Behav Immun 2009; 23:267-75. doi:10.1016/j. bbi.2008.10.005

16 Reiche EM, Nunes SO, Morimoto HK. Stress, depression, the immune system and cancer. Lancet Oncol 2004; 5:617-25. doi:I0.10I6/SI470-2045(04)0I597-9

17 Danese A, Pariante CM, Caspi A et al. Childhood maltreatment predicts adult inflammation in a life-course study. Proc Natl Acad Sci USA 2007; 104:1319-24. doi:10.1073/pnas.0610362104

I8 Feliti VJ, Anda RF, Nordenberg D et al. Relationship of childhood abuse and household dysfunction to many of the leading causes of death in adults: the adverse childhood experience (ACE) study. Am J Prev Med 1998; I4:245-58. doi: 10.1016/S0749-3797(98)000I7-8

19 Spiegel D, Bloom JR, Kraemer HC et al. Effect of psychosocial treatment on survival of patients with metastatic breast cancer. Lancet 1989; 2:888-91. doi:I0.1016/S0I40-6736(89)9|55I-I

20 Goodwin PJ, Leszcz M, Ennis M et al.The effect of group psychosocial support on survival in metastatic breast cancer. N Engl J Med 200I; 345:1719-26. doi:I0.1056/NEJMoa0I 187|

21 Spiegel D, Butler LD, Giese-Davis L et al. Effects of supportiveexpressive group therapy on survival of patients with metastatic breast cancer: a randomized prospective trial. Cancer 2007; I 10:1 130-38. doi:I0.1002/cncr.22890
22 Fawzy Fl, Canada AL, Fawzy NW. Malignant melanoma: effects of a brief, structured psychiatric intervention on survival and recurrence at 10 year follow up. Arch Gen Psychiatry 2003; 60:100103. doi: $10.1001 /$ archpsyc.60.1.100

23 Kiecolt-Glaser JK, Gouin JP, Hantsoo L. Close relationships, inflammation and health. Neurosci Biobehav Rev 2010; 35:33-38.

24 Lutgendorf SK,DeGeest K, Dahmoush L et al. Social isolation is associated with elevated tumour epinephrine in ovarian carcinoma patients. Brain Behav Immun 20II; 25:250-55. doi:/0.1016/j. bbi.2010.10.012

25 Melhem-Bertrandt A, Chavez-MacGregor M, Lei $X$ et al. Betablocker use is associated with improved relapse-free survival in patients with triple-negative breast cancer. I Clin Oncol 201I; 29:2645-52. doi:|0.|200/JCO.20I0.33.444|

26 Barron TI,Connolly RM, Sharp L et al. Beta blockers and breast cancer mortality: a population-based study. I Clin Oncol 201I, 29:2635-44. doi: $10.1200 / J C O .2010 .33 .5422$

27 Ganz PA, Cole SW. Expanding our therapeutic options: beta blockers for breast cancer? J Clin Oncol 201I; 29:26I2-16. doi: $10.1200 / J C O .2011 .35 .8820$

28 Proctor MJ, Morrison DS, Talwar D et al. A comparison of inflammation-based prognostic scores in patients with cancer. A Glasgow Inflammation Outcome Study. Eur J Cancer 20I I. In Press.

29 McMillan DC. Systemic inflammation, nutritional status and survival in patients with cancer. Curr Opin Clin Nutr and Metab Care 2009;12:22326. doi:I0.1097/MCO.0b013e32832a7902

30 Slaviero KA, Clarke SJ, Rivory LP. Inflammatory response: an unrecognized source of variability in the pharmacokinetics and pharmacodynamics of cancer chemotherapy. Lancet Oncol 2003; 4:224-32. doi: $10.1016 / 51470-2045(03) 01034-9$

3I Seruga B, Zhang $H$, Bernstein LJ et al. Cytokines and their relationship to the symptoms and outcome of cancer. Nat Rev Cancer 2008; 8:887-89. doi:I0.1038/nrc2507

32 MacDonald N, Kasymjanova G, Gagnon B, et al. Markers of a chronic inflammatory state and trial completion: Data from cancer cachexia trial. In: J Clin Oncol (Meeting Abstracts)2008;9594.

33 Kasymjanova G, MacDonald N, Agulnik JS et al. The predictive value of pre-treatment inflammatory markers in advanced nonsmall cell lung cancer. Current Oncology 20 10; 17:52-58. doi:10.3747| co.v17i4.567

34 Crumley $A B$, Stuart RC, McKernan $M$ et al. Comparison of an inflammation-based prognostic score (GPS) with performance status (ECOG-ps) in patients receiving palliative chemotherapy for gastroesophageal cancer.J Gastroenterol Hepatol 2008; 23:e325-e329. doi:I0.IIIII/j.1440-1746.2007.05I05.x

35 Ishizuka M, Nagata $\mathrm{H}$, Kazutoshi T et al. Influence of inflammationbased prognostic score on mortality of patients undergoing chemotherapy for far advanced or recurrent unresectable colorectal cancer. Ann Surg 2009; 250:268-72. doi:10.1097| SLA.0b013e318IbI6e24

36 Simpson N, Dinges DF. Sleep and inflammation. Nutr Rev 2007; 65:S244-S252. doi:I0.1301/nr.2007.dec.S244-S252

37 Eismann EA, Lush E, Sephton SE. Circadian effects in cancer-relevant psychoneuroendocrineandimmunepathways.Psychoneuroendocrinology 2010: 35:963-76. doi:I0.1016/j.psyneuen.2009.12.01I

38 Schubert C, Hong S, Natarajan L et al. The association between fatigue and inflammatory marker levels in cancer patients: a quantitative review. Brain Behav Immun 2007; 21:413-27. doi:10.1016/j.bbi.2006.11.004

39 Park J, $\mathrm{Ha} \mathrm{M}, \mathrm{Yi}$ Y et al. Subjective fatigue and stress hormone levels in urine according to duration of shiftwork. J Occup Health 2006; 48:446-50. doi:I0.1539/joh.48.446

40 Wyller V, Saul J, Walloe L et al. Sympathetic cardiovascular control during orthostatic stress and isometric exercise in chronic adolescent chronic fatigue syndrome. Eur J Appl Physiol 2008; 102:623-32. doi:|0.1007/s0042I-007-0634-I 
4I Fagundes CP, Murray DM, Hwang BS et al. Sympathetic and parasympathetic activity in cancer-related fatigue: more evidence for a physiological substrate in cancer survivors. Psychoneuroendocrinology 201 I; [epub ahead of print] doi: I0.1016/j.psyneuen.20II.02.005

42 Jae SY, Heffernan KS, Yoon ES et al. The inverse association between cardiorespiratory fitness and c-reactive protein is mediated by autonomic function: a possible role of the cholinergic anti-inflammatory pathway. Mol Med 2009; 15:291-96.

43 Ford DE, Erlinger TP. Depression and C-reactive protein in US adults. Arch Intern Med 2004; 164:1010-14. doi:10.100I/ archinte.164.9.1010

44 Illman J, Corringham R, Robinson D et al. Are inflammatory cytokines the common link between cancer-associated cachexia and depression? J Support Oncol 2005; 3:37-50.

45 Laviano A, Inui A, Marks DL et al. Neural control of the anorexiacachexia syndrome. Am J Physiol Endocrinol Metab 2008; 295: 1000 1008. doi:I0.I I52/ajpendo.90252.2008

46 Krasnow SM, Marks D. Neuropeptides and the pathophysiology and treatment of cachexia. Curr Opin Support Palliat Care 2010; 4:266-7I. doi: 10.1097/SPC.0b013e32833e48e7

47 Grossberg AJ, Scarlett JM, Marks DL. Hypothalamic mechanisms in cachexia. Physiology Behav 2010; 100:478-89. doi:10.1016/j. physbeh.2010.03.011

48 De Boer MD, Scarlett, JM, Levasseur PR et al. Administration of IL-Ibeta to the 4th ventricle causes anorexia that is blocked by agouti-related peptide and that coincides with activation of tyrosine-hydroxylase neurons in the nucleus of the solitary tract. Peptides 2009; 30:210-18. doi:10.1016/j.peptides.2008.10.019

49 Brisbois Clarkson T, De Kock IH, Watanabe S et al. Delta-9tetrahydrocannabinol may be useful to palliate altered chemosensory perception in cancer patients: results of a randomized, double-blind, placebo-controlled pilot trial. Ann Oncol 20I I: In Press.

50 Fearon K, Strasser F,Anker SD et al. Definition and classification of cancer cachexia: an international perspective. Lancet Oncol 20I I; 12:489-95.

5I Prado CM, Baracos VE, McCargar LJ et al. Body composition as an independent determinant of 5-fluorouracil-based chemotherapy toxicity. Clin Cancer Res 2007; I 3:3264-68. doi: I0. I I58/I 078-0432. CCR-06-3067

52 Prado CM, Baracos VE, McCargar LJ et al. Sarcopenia as a determinant of chemotherapy toxicity and time to tumor progression in metastatic breast cancer patients receiving capecitabine treatment. Clin Cancer Res 2009: 15:2920-26. doi: I0.1 I58/I078-0432.CCR-08-2242

53 Tan BHL, Birdsell LA, Martin L et al. Sarcopenia in an overweight or obese patient is an adverse prognostic factor in pancreatic cancer. Clin Cancer Res 2009; I5:6973-79. doi:I0.I I58/I078-0432. CCR-09-I525

54 Acharyya S, Ladner KJ, Nelsen LL et al. Cancer cachexia is regulated by selective targeting of skeletal muscle gene products.J Clin Invest 2004; II4:370-78.

55 Tisdale M. Mechanisms of cancer cachexia. Physiol Rev 2009; 89:381-410. doi:I0.1I52/physrev.00016.2008

56 Dodson S, Baracos VE, Jatoi A et al. Muscle wasting in cancer cachexia: clinical implications, diagnosis and emerging treatment strategies. Annu Rev Med 201 I; 62:265-79. doi:10.1146/annurevmed-061509-131248

57 Guttridge DC. Signaling pathways weigh in on decisions to make or break skeletal muscle. Curr Opin Clin Nutr Metab Care 2004; 7:44350. doi:I0.1097/0I.mco.0000134364.6I406.26

58 Lenk K, Schuler G, Adams V. Skeletal muscle wasting in cachexia and sarcopenia: molecular pathophysiology and impact of exercise training. J Cachex Sarcopenia Muscle 2010; I:9-21. doi:|10.1007/ sI3539-010-0007-I

59 Sauer LA, Dauchy RT, Blask DE. Mechanism for the antitumor and anticachectic effects of n-3 fatty acids. Cancer Res 2000; 60:5289-95.
60 Colomer R, Moreno-Nogueira JM, Garcia-Luna P et al. N-3 fatty acids, cancer and cachexia: a systematic review of the literature. Br J Nutr 2007; 97:823-3I. doi:I0.10I7/S0007||450765795X

6I Fearon KC, von Meyenfeldt MF, Moses AG et al. Effect of a protein and energy dense $\mathrm{n}-3$ fatty acid enriched oral supplement on loss of weight and lean tissue in cancer cachexia: a randomized double blind trial. Gut 2003; 52: 1479-86. doi:I0.1 I36/gut.52.10.1479

62 Lundholm K, Gelin J, Hyltander A et al. Anti-inflammatory treatment may prolong survival in undernourished patients with metastatic solid tumors. Cancer Res 1994: 54:5602-06.

63 Lundholm K, Daneryyd P, Korner $U$ et al. Evidence that long-term COX-treatment improves energy homeostasis and body composition in cancer patients with progressive cachexia. Int J Oncol 2004; 24:505-12.

64 Zilbermint MF, Dobs AS. Nonsteroidal selective androgen receptor modulator ostarine in cancer cachexia. Future Oncol 2009; 5:121120. doi: $10.2217 /$ fon.09.106

65 Ceglia L.Vitamin D and its role in skeletal muscle. Curr Opin Clin Nutr Metab Care 2009; 12:628-33. doi:10.1097/ MCO.0b013e32833Ic707

66 Ryall JG, Lynch GS. The potential and the pitfalls of $\beta$ adrenoreceptor agonists for the management of skeletal muscle wasting. PharmacolTher 2008; 120:219-32. doi:10.1016/j.pharmthera.2008.06.003

67 Lainscak M, Keber I, Anker SD. Body composition changes in patients with systolic heart failure treated with beta-blockers: a pilot study. Int J Cardiol 2006; 106:319-22. doi:10.1016/j. ijcard.2005.01.06I

68 Herndon DN, Hart DW, Wolf SE et al. Reversal of catabolism by beta-blockade after severe burns. N Engl J Med 200 I; 345: I223-29. doi:I0.1056/NEJMoa010342

69 Fadul N.Autonomic system modulators. In: Del Fabbro E, Baracos V, Demark-Wahnefried et al editors. Nutrition and the cancer patient. New York: Oxford University Press; 2010.

70 Clarke S, Gebbie C, Sweeney C et al. A phase I, pharmacokinetic (PK) and preliminary efficacy assessment of ALD5/8, a humanized antiIL-6 antibody, in patients with cancer. 5th Cachexia Conference, Barcelona 2009. Abstract 142: p. 15.

7I Zhou X,Wang JL, Lu J et al. Reversal of cancer cachexia and muscle wasting by ActRIIB antagonism leads to prolonged survival. Cell 20I0; |42:53I-43. doi:|0.10I6/j.cell.2010.07.0II

72 Lundholm K, Daneryd P, Korner $U$ et al. Evidence that long-term COX-treatment improves energy homeostasis and body composition in cancer patients with progressive cachexia. Int J Oncol $2004 ; 24: 505-12$ 